\title{
CSF monoamine metabolites, cholinesterases and lactate in the adult hydrocephalus syndrome (normal pressure hydrocephalus) related to CSF hydrodynamic parameters
}

\author{
Jan Malm, B Kristensen, Jan Ekstedt, Rolf Adolfsson, Per Wester
}

\begin{abstract}
Monoamine metabolites, cholinesterases and lactic acid in lumbar cerebrospinal fluid (CSF) were investigated on patients with the adult hydrocephalus syndrome (idiopathic normal pressure syndrome; AHS, $n=15$ ), Alzheimer's disease (AD, $n=14$ ), multi-infarct dementia (MID, $n=13)$ and controls $(n=21)$. Patients had clinical and CSF hydrodynamic investigations. Monoamine concentrations were determined by reversed-phase liquid chromatography, cholinesterases and lactate were determined photometrically. In the AHS patients, CSF monoamine concentrations were not significantly different compared with controls, AD or MID patients. AHS and AD patients showed a similar reduction of CSF acetylcholinesterase activity compared with controls. Positive correlations were found in concentrations of CSF homovanillic acid, CSF 5-hydroxyindoleacetic acid and CSF lactic acid versus CSF outflow conductance (that is, resistance against CSF outflow) in the AHS patients. A similar pattern was observed in a subgroup of MID patients characterised by dilated ventricles and disturbed CSF hydrodynamics. These data suggest that a low CSF outflow conductance may facilitate the clearance of acidic substances from the arachnoid space at the probenicid sensitive active transport site. Alternative explanations would be that a pathologically low CSF outflow conductance is accompanied by an inverse caudorostral flow of CSF or a compromised transependymal diffusion.
\end{abstract}

Hakim in $1964^{1}$ and Hakim and Adams ${ }^{2}$ in 1965 described a condition clinically characterised by a triad including gait disturbance, cognitive decline and urine sphincter incontinence, accompanied by communicating hydrocephalus. Different names have been attached to the syndrome (for example, normal pressure hydrocephalus) and caused a great deal of confusion because the pressure was not considered to be below normal but the increase in pressure was considered low. In a recent symposium discussion, no agreement could be reached about the name of the syndrome. ${ }^{3}$ We consider the adult hydrocephalus syndrome (AHS) to be the more appropriate description for the condition. In contrast to the more commonly occurring Alzheimer's disease (AD) and multi-infarct dementia (MID), the progress of AHS can be ameliorated by a ventriculoperitoneal shunt. ${ }^{4}$

Specific biochemical disorders have been observed in $\mathrm{AD}$ and MID, ${ }^{5}$ with a disturbance in the acetylcholine system in $\mathrm{AD}$ as the most consistent finding ${ }^{67}$ as well as serotonergic and noradrenergic deficits. ${ }^{5}$ Therefore, a cholinergic deficit could be predicted in AHS patients, especially in those with a severe dementia. Parkinson's disease is characterised primarily as a dysfunction of the dopaminergic nigrostriatal and mesocortical pathways, ${ }^{8}$ although cholinergic, serotonergic and noradrenergic deficits have also been reported. ${ }^{9}$ The walking dysfunction in AHS patients is dyspractic and reminiscent of a Parkinsonian gait disorder. ${ }^{10}$ There are case reports of successful treatment with levodopa of AHS patients. ${ }^{11}$ One might therefore expect a dopaminergic deficiency in AHS patients.

It is well known that AHS patients have disturbed CSF hydrodynamics, that is, low CSF outflow conductance and a normal or slightly elevated intracranial pressure. ${ }^{1213}$ Moreover, if a radionuclide is injected in the lumbar CSF space, there will be a reflux into ventricles. ${ }^{14}$ It would thus be reasonable to assume, that alterations in these CSF flow mechanisms could alter the biochemical profile in the CSF subarachnoid space in AHS patients.

Few attempts have been made to characterise the monoaminergic profile in idiopathic AHS patients, with the finding of normal or low concentrations of lumbar CSF homovanillic acid and normal levels of 5-hydroxyindoleacetic acid, ${ }^{15} 16$ while the cholinergic system has so far, to our knowledge, not been studied.

The purpose of this study was to elucidate whether AHS patients have a different monoamine or cholinergic transmitter profile than control, AD or MID patients. Furthermore, clinical assessments and CSF hydrodynamics have been related to CSF transmitter marker profiles.

\section{Material and methods}

Patients Patients who were found to have hydrocephalus on CT scan or a walking disturbance and were suspected of AHS were admitted to the Department of Neurology, University of Umeå between 1982-87. 
Table 1 Sample description

\begin{tabular}{lllll}
\hline Clinical variable & $\begin{array}{l}\text { Controls } \\
(n=21)\end{array}$ & $\begin{array}{l}A H S \\
(n=15)\end{array}$ & $\begin{array}{l}M I D \\
(n=13)\end{array}$ & $\begin{array}{l}A D \\
(n=14)\end{array}$ \\
\hline $\begin{array}{llll}\text { Age (year) } \\
\text { Sex (male/female) }\end{array}$ & $73 \cdot 8(8 \cdot 2)$ & $73 \cdot 2(6 \cdot 1)$ & $73 \cdot 1(4 \cdot 7)$ & $71 \cdot 2(4 \cdot 0)$ \\
$\begin{array}{l}\text { Duration of illness (month) } \\
\text { Dementia severity (\%) }\end{array}$ & $14 / 7$ & $12 / 3$ & $8 / 5$ & $5 / 9$ \\
$\quad \begin{array}{l}\text { none } \\
\text { mild }\end{array}$ & - & $25 \cdot 3(12 \cdot 4)$ & $32 \cdot 9(33 \cdot 3)$ & $42 \cdot 1(20 \cdot 2)$ \\
$\begin{array}{l}\text { moderate } \\
\text { severe }\end{array}$ & - & 20 & 0 & 0 \\
MMSE (points) & - & 60 & 13 & 7 \\
Hachinski score (points) & - & 7 & 46 & 50 \\
\hline
\end{tabular}

Values are given as mean (SD). Abbreviations; AHS = Adult hydrocephalus syndrome; MID = Multiinfarct dementia; $A D=$ Alzheimer's disease; MMSE = minimental state examination.

Patients with a clear diagnosis of adult hydrocephalus syndrome, Alzheimer's disease or multiinfarct dementia were included in this study according to the following criteria (the patient groups are described in tables 1 and 2):

AHS patients: all cases had the typical gait abnormality and either dementia or urine incontinence and an ischaemic score less than five according to Hachinski. ${ }^{17} \mathrm{CT}$ scan showed communicating hydrocephalus with Evans ratio $>0 \cdot 3$. CSF hydrodynamic investigation revealed a conductance below $12 \mathrm{~mm}^{3} \mathrm{kPa}^{-1}$ $\mathrm{sec}^{-1}$ and a normal or slightly increased intracranial pressure. All but three patients showed improved ability to walk after a CSF tap test or after insertion of a shunt. None of the patients with AHS had a precipitating cause such as traunia, subarachnoid haemorrhage or meningitis and were thus considered to be of idiopathic type. None of the patients were taking neuroactive drugs.

$A D$ and $M I D$ patients: 60 patients fulfilled the criteria of dementia according to DSM III. ${ }^{18}$ The dementia patients were allocated on clinical criteria into one of three categories: 1) AD, 2) MID and 3) dementia of other type. This was carried out by four neurologists and one psychiatrist who, independently of each other, judged every dementia patient. The clinical diagnoses were based on case history, clinical investigation and laboratory findings as described below. When there was a disagreement between the judges $(n=25)$ or if the patient was considered to be suffering from another dementia type (alcohol induced dementia, $n=3$; status lacunaris, $n=3$, Pick's disease, $n=1$ ), the patient was excluded from this study. The criteria for diagnosis of $\mathrm{AD}$

Table 2 CSF hydrodynamic and CT scan parameters

\begin{tabular}{|c|c|c|c|c|}
\hline & $\begin{array}{l}\text { AHS } \\
(n=15)\end{array}$ & $\begin{array}{l}M I D^{\star} \\
(n=6)\end{array}$ & $\begin{array}{l}M I D \dagger \\
(n=7)\end{array}$ & $\begin{array}{l}A D \\
(n=14)\end{array}$ \\
\hline \multicolumn{5}{|l|}{ CSF hydrodynamics } \\
\hline Lumbar resting pressure $(\mathrm{kPa})$ & $2 \cdot 2(0 \cdot 4)$ & $1.7(0.6)$ & $1.8(0 \cdot 2)$ & $1.4(0 \cdot 3)$ \\
\hline $\begin{array}{l}\text { Conductance of CSF outflow pathways } \\
\left(\mathrm{mm}^{3} \mathrm{kPa}^{-1} \mathrm{sec}^{-1}\right)\end{array}$ & $5 \cdot 8(2 \cdot 4)$ & $7 \cdot 4(1.5)$ & $18 \cdot 3(9 \cdot 1)$ & $16 \cdot 3(5 \cdot 3)$ \\
\hline \multicolumn{5}{|l|}{ CT scan } \\
\hline \multicolumn{5}{|l|}{ Hydrocephalus } \\
\hline moderate & 6 & 3 & 5 & 8 \\
\hline severe & 9 & 3 & 1 & 0 \\
\hline White matter low attenuation & 10 & 3 & 3 & 3 \\
\hline $\begin{array}{l}\text { paraventricular } \\
\text { Cortical atrophy }\end{array}$ & 0 & 2 & 3 & 11 \\
\hline Infarction & 1 & 1 & 4 & 0 \\
\hline
\end{tabular}

Values are given as mean $(\mathrm{SD}) ; \mathrm{MID}^{\star}$, patients with $\mathrm{CSF}$ outflow conductance lower than $10 \mathrm{~mm}^{3} \mathrm{kPa}^{-1} \mathrm{sec}^{-1}$; MIDt, patients with CSF outflow conductance higher than $10 \mathrm{~mm}^{3} \mathrm{kPa}^{-1} \mathrm{sec}^{-1}$. $1 \mathrm{kPa}=102 \mathrm{~mm} \mathrm{H} \mathrm{H}_{2} \mathrm{O}=7.5 \mathrm{~mm} \mathrm{Hg} ; 1 \mathrm{~mm}^{3} \mathrm{kPa}^{-1} \mathrm{sec}^{-1}=6 \times 10^{-3} \mathrm{~m}$ $\left(\mathrm{cmH}_{2} \mathrm{O}\right)^{-1}=8 \times 10^{-3}(\mathrm{~mm} \mathrm{Hg})^{-1} \mathrm{~min}^{-1}$. were a continuous progression of cognitive decline without any focal neurological signs except for aphasia, agnosia or apraxia, ${ }^{18}$ a CT scan that did not show brain lesions, and a Hachinski score of less than four. The diagnosis of MID was based on a case history of fluctuation or stepwise progression of cognitive decline and focal neurological signs that could be related to cerebrovascular disease ${ }^{19}$; the Hachinski score was more than seven in all but four of these patients. Two MID patients were receiving neuroleptic treatment; one patient with MID and one with $A D$ were taking antidepressants.

Controls: orthopaedic or urological patients without known psychiatric or neurological disorders were chosen as controls; the CSF samples were obtained immediately before spinal anaesthesia. CT scan investigations were not performed on these subjects.

\section{Clinical investigation}

Case history: included duration of illness (dementia for the AD and MID patients; gait disturbance for AHS patients), type of dementia progression (continuous/stepwise), previous history of vascular risk factors and previous somatic/neurological/psychiatric disorders. Each patient was assigned to one of five functional grades according to Stein and Langfitt $^{20}$ and an ischaemic score was obtained. ${ }^{17}$

Laboratory tests: laboratory investigations were performed to discover reversible and treatable causes of dementia, including examination of the CSF and EEG. A CSF tap-test was conducted in the AHS group and among most of the patients within the MID or $\mathrm{AD}$ groups.

Walking disturbance: three independent observers studied video recordings of the AHS patients and graded them according to a $0-5$ degree scale with $0=$ no disturbance and $5=$ a severe gait dyspraxia.

Measurement of cognitive decline: the degree of dementia was graded with a $0-3$ level scale, $0=$ no dementia and $3=$ severely demented. In the AHS patients, a Mini-Mental State Estimation (MMSE) ${ }^{21}$ was performed.

Incontinence: the degree of urinary incontinence in the AHS group ranged from $0=$ no incontinence to $5=$ continuous use of catheter á démeure.

Computed Tomography: CT scans were reviewed by neuroradiologists who rated the width of the ventricles (no, moderate or severe hydrocephalus), the degree of cortical atrophy and the occurrence of low density periventricular areas. In patients with AHS, the Evans ratio and the width of the third ventricle were also measured.

CSF sampling, CSF hydrodynamic investigation The CSF hydrodynamic investigation was performed according to the method described by Ekstedt. ${ }^{22}$ Briefly, at 8 am, after 12 hours bed rest, two needles were inserted in the L3-L4 space. CSF ( $2 \mathrm{ml})$ was aspirated to check for free CSF passage; this CSF sample was immediately frozen at $-70^{\circ} \mathrm{C}$ until biochemical tests were performed. The patient was placed in the supine position with the zero 
pressure reference level at the cranial sagittal centre. Drainage of CSF and infusion of artificial CSF was made to and from a continuously weighed bottle. The pressure in the bottle was regulated by means of an electronic control system acting on the fluid in the bottle by means of the air pressure from a pump.

The CSF resting pressure was determined when the resting recording had been stable for, at least 10 minutes, which usually required 30 60 minutes recording. The conductance of the CSF outflow pathways was determined by applying multiple pressure levels to the CSF space while recording the resulting inflow of artificial CSF into the patient. Thus within a few minutes a stable flow at a stable pressure was obtained. Usually, three different pressure/ flow values could be obtained. These values were then used to calculate the pressure/flow relationship. The slope for the pressure/flow values is equal to the CSF outflow conductance. The CSF formation rate was determined by lowering the CSF pressure to a value of about 0 $\mathrm{kPa}$ for a time long enough to get a stable pressure and outflow into the bottle. Thus about $30-40 \mathrm{ml}$ of CSF was drained and the patient was left with a CSF pressure about 0 $\mathrm{kPa}$. The clinical effect of lowering CSF pressure in this way would be similar to the effect of the CSF tap-test according to Wikkelsö. ${ }^{23} \mathrm{Clin}$ ical parameters such as walking disturbance, memory and fine skilled movements in arms were tested at $1 \mathrm{pm}$ the day before and the same day as the CSF hydrodynamic investigation was performed.

Assessment of monoamine concentrations Concentrations of 3-methoxy-4-hydroxyphenylglycol (MHPG), homovanillic acid (HVA) and 5-hydroxyindoleacetic acid (5HIAA) were determined simultaneously by reversed phase isocratic liquid chromatography with electrochemical detection essentially as described elsewhere.$^{24}{ }^{25}$ Briefly, to each $90 \mu \mathrm{l}$ of $\mathrm{CSF}, 10 \mu \mathrm{l}$ of $1 \mathrm{M}$ perchloric acid (containing $0.3 \mathrm{mM} \mathrm{Na} \mathrm{mDTA}_{2}$, $0.5 \mathrm{mM}$ $\mathrm{Na}_{2} \mathrm{SO}_{3}, \quad 0.5 \mu \mathrm{M}$ isoproterenol (internal standard) and 2500 IE heparin) were added. The samples were vortexed, centrifuged at $48000 \mathrm{~g}$ for 30 minutes at $+4^{\circ} \mathrm{C}$, taken through a $0.60 \mu \mathrm{M}$ Millipore filter and $50 \mu \mathrm{l}$ was then directly injected into the chromatographic system. The isocratic mobile phase, with a flow rate of $1.2 \mathrm{ml} / \mathrm{min}$, consisted of a $100 \mathrm{mM}$ citrate buffer including $0.3 \mathrm{mM} \mathrm{Na} \mathrm{N}_{2}$ EDTA, $0.334 \mathrm{mM}$ octylsulphate; $5 \cdot 5 / 94.5 \%$ ( $\mathrm{vol} / \mathrm{vol}$ ) acetonitrile/water at a $\mathrm{pH}$ of $2 \cdot 35$. The stationary phase consisted of a $170 \times 4.6 \mathrm{~mm}$ stainless steel column packed with Nucleosil C-18, $5 \mu \mathrm{m}$ (batch no 5061) from Macherey-Nagel (Düren, Germany), the column temperature was controlled by means of a plastic jacket coupled to a water thermostat that was set at $+25^{\circ} \mathrm{C}$. The substances were detected electrochemically with a Coulochem ESA detector (Environmental Sciences Associates 5100A, Bedford, MA, USA) with an analytical cell, model 7021 . A guard cell (placed before the SIL 6A, Shimadzu autoinjector) was set at $+1.05 \mathrm{~V}$ (to minimise background noise), the first detector cell at $+0 \cdot 10 \mathrm{~V}$ (to avoid a negative deflection in the baseline) and the second detector cell (coupled to the integrator) at $+0.55 \mathrm{~V}$ versus paladium reference electrode. The detector was coupled to an integrator, model CI10 (Laboratory Data Control, Riviera Beach, FL, USA). The recoveries for the substances as measured in CSF were in the range between $94-99 \%{ }^{25}$ The coefficient of variation (CV) showed an average value of $1.8 \%$ for standards and $2 \cdot 1 \%$ for CSF samples. ${ }^{25}$

\section{Assessment of cholinergic markers}

Acetylcholinesterase (AChE, EC3.1.1.7) and butyrylcholinesterase (BuChE, EC3.1.1.8) were measured photometrically according to a modification of the method described by Ellman, 1961..$^{26} 100 \mu \mathrm{l} \mathrm{CSF}$ was used for each assay in a total volume of $500 \mu \mathrm{l}$. The assay medium consisted of $0 \cdot 1 \mathrm{M}$ sodium phosphate buffer, $\mathrm{pH} 8.0$ and either $1 \mathrm{mmol} / \mathrm{l}$ of acetylthiocholine or butyrylthiocholine as substrates for $\mathrm{AChE}$ and $\mathrm{BuChE}$ respectively. In order to specifically inhibit BuChE activity when measuring $\mathrm{AChE}$ activity, the samples were incubated for 15 minutes with $3.75 \times 10^{-5} \mathrm{~mol} / 1$ iso-OMPA. Similarly, to specifically inhibit AChE activity when measuring $\mathrm{BuChE}$ activity, the samples were incubated with the inhibitor BW 284C51, final concentration $4 \times 10^{-6} \mathrm{~mol} / \mathrm{l}$. Values given are corrected for spontaneous hydrolysis of the substrates.

\section{Lactic acid determination}

L-lactic acid concentrations in CSF were determined photometrically according to a modification of the method described by Noll. ${ }^{27}$ Lactic acid assay kits (Cat 256 773) were purchased from Boehringer and Mannheim. Briefly, $50 \mu \mathrm{l}$ of CSF was added to $5 \mathrm{ml}$ of carbonate buffer including NAD. To $2.5 \mathrm{ml}$ of this solute, $50 \mu \mathrm{l}$ of ammonium sulphate was added, to the other $2.5 \mathrm{mls} 50 \mu \mathrm{l}$ of $\mathrm{LDH} / \mathrm{L}$ alanine: 2-oxoglutarate aminotransferase was added. The solutes were mixed and incubated for 20 minutes, and the difference of the absorbance was monitored in the two media.

\section{Statistical analysis}

All statistical analyses were conducted using the System for Statistics. ${ }^{28}$ Comparisons of transmitter markers between different diagnostic groups were evaluated by analysis of variance (ANOVA) followed by post-hoc tests. Linear regression analyses between the CSF transmitter variable versus the different clinical variables were performed where the regressors were tested in the models using $t$-test $(\mathrm{HO}=0)$ and regarded as statistically significant when the corresponding p-value was below 0.05 .

\section{Results}

Comparison of CSF transmitter markers in patients with the adult hydrocephalus syndrome versus controls, Alzheimer's disease and multiinfarct dementia (table 3)

MHPG concentrations did not differ significantly between the different groups (ANOVA; $F=0.55, p>0.6)$. No differences were seen 
Table 3 CSF neurotransmitter and metabolic markers in patients with adult hydrocephalus syndrome (AHS) in comparison with controls, multiinfarct dementia (MID) and Alzheimer's disease ( $A D$ )

\begin{tabular}{|c|c|c|c|c|}
\hline & Controls & $A H S$ & $M I D$ & $A D$ \\
\hline $\begin{array}{l}\text { MHPG } \\
\text { 5-HIAA } \\
\text { HVA } \\
\text { ACHE } \\
\text { BUCHE } \\
\text { LACTATE }\end{array}$ & $\begin{array}{c}46 \cdot 4(33 \cdot 4) \\
157(191) \\
243(102) \\
45 \cdot 3(12 \cdot 4) \\
21 \cdot 2(6 \cdot 09) \\
2 \cdot 10(0 \cdot 47)\end{array}$ & $\begin{array}{c}35 \cdot 2(7 \cdot 38) \\
129(64 \cdot 8) \\
224(100) \\
36 \cdot 2^{\mathrm{a}}(8 \cdot 3) \\
19 \cdot 1(5 \cdot 77) \\
1 \cdot 74^{\mathrm{c}}(0 \cdot 28)\end{array}$ & $\begin{array}{c}39 \cdot 1(12 \cdot 0) \\
163(66 \cdot 4) \\
250(133) \\
38.5(8.52) \\
21.8(8.61) \\
1.96(0.31)\end{array}$ & $\begin{array}{c}36 \cdot 3(8 \cdot 86) \\
153(63 \cdot 0) \\
247(104) \\
36 \cdot 5^{\mathrm{b}}(5 \cdot 58) \\
16 \cdot 6(4 \cdot 27) \\
1 \cdot 70^{\mathrm{d}}(0 \cdot 20)\end{array}$ \\
\hline
\end{tabular}

Values are given as mean (SD) in $\mathrm{nmol} / \mathrm{l} \mathrm{CSF}$ for monoamine metabolites and lactic acid and in $\mathrm{nmol} / \mathrm{min} / \mathrm{l} \mathrm{CSF}$ for cholinesterase activities. ${ }^{2-b}$ Significantly reduced compared with controls; ${ }^{a} \mathrm{~F}=7.66, \mathrm{p}<0.01 ;{ }^{b} \mathrm{~F}=6.95, \mathrm{p}<0.05{ }^{c-d}$ Significantly reduced compared with controls; ${ }^{\mathrm{c}} \mathrm{F}=7.69, \mathrm{p}<0.01 .{ }^{\mathrm{d}} \mathrm{F}=9.83, \mathrm{p}<0.01$. When comparing CSF ted comitter markers in AHS vs $A D$ and MID patients, no significant differences were found (ANOVA, $p<0 \cdot 1$ ).

between the AHS group versus the controls, the $A D$ group or the MID group ( $p>0.3$ ).

HVA concentrations were not different between the diagnostic groups (ANOVA; $\mathrm{F}=0 \cdot 16, \mathrm{p}>0.9)$. No significant differences were found between the AHS versus controls, $A D$ patients and MID patients ( $p>0.5)$.

5-HIAA concentrations showed no difference between the diagnostic groups (ANOVA; $\mathrm{F}=0.21, \mathrm{p}>0.8$ ). No significant change was seen between the AHS group and the controls, the $\mathrm{AD}$ group and the MID group $(\mathrm{p}>0.4)$.

AChE activities differed between the diagnostic groups (ANOVA; $F=3.39, p<0.02$ ). Significantly reduced AChE activity was observed in the $\mathrm{AHS}$ and $\mathrm{AD}$ group versus controls $(80 \%$ of control values for AHS, $F=7.66, p<0.01 ; 81 \%$ of control values for $\mathrm{AD}, \mathrm{F}=6.95, \mathrm{p}<0.05)$ while the CSF AChE in the AHS group did not differ from the $A D$ group or the MID group ( $p>0.5$ ).

BuChE activities showed no differences between diagnostic groups (ANOVA; $F=2 \cdot 06$, $\mathrm{p}>0 \cdot 1)$. CSF BuChE activity was without significant difference in the AHS group versus controls, AD and MID patients ( $p>0 \cdot 2$ ).

Lactic acid concentrations differed between the diagnostic groups (ANOVA; $F=4 \cdot 25, p<$ $0 \cdot 01)$. Significantly reduced lactate concentrations were observed in the AHS group versus controls $(83 \%$ of controls, $F=7 \cdot 69, p<$ 0.01 ) and also in the $\mathrm{AD}$ group compared with controls $(F=9.83, p<0.01)$ while no other differences were detected.

Influence of CSF outflow conductance, resting pressure and CSF formation rate on CSF transmitter and metabolic markers

In fig 1, the relationship between CSF HVA concentrations and CSF outflow conductance level is presented. As can be seen, a positive correlation was observed for CSF HVA versus CSF outflow conductance in the AHS group (fig la, linear regression; $r=+0.74, p<0.001$ ) while in the MID group and the AD group no such relationship was observed (fig $1 \mathrm{~b}$ and $1 \mathrm{c}$ ). However, in MID patients with a CSF outflow conductance below $15 \mathrm{~mm}^{3} \mathrm{kPa}^{-1} \mathrm{sec}^{-1}$ a similar pattern as in the AHS group was observed (fig $1 \mathrm{~b}$; linear regression, $\mathrm{r}=+0.88, \mathrm{p}<0.01$ ).

A positive correlation was observed between CSF 5-HIAA concentration versus CSF outflow conductance in the AHS group (fig 2a,
Figure 1a-c CSF homovanillic acid concentrations versus CSF outflow conductance in patients with the adult hydrocephalus syndrome (fig 1a; linear regression, $n=15, r=+0 \cdot 74$, $p<0.001$ ), multiinfarct dementia (fig $1 b$; linear regression, $n=13$, $r=+0 \cdot 26, p>0 \cdot 3)$ and Alzheimer's disease (fig 1c; linear regression; $n=12, r=-0 \cdot 24, p>$ 0.4). In MID patients with a CSF outflow conductance value below $15 \mathrm{~mm}^{3} \mathrm{kPa}^{-1} \mathrm{sec}^{-1}, a$ positive correlation was observed between CSF HVA versus CSF outflow conductance (linear regression; $n=9$ $r=+0.88, p<0.01$, equation $y=-73 \cdot 0+35 \cdot 0 x)$.
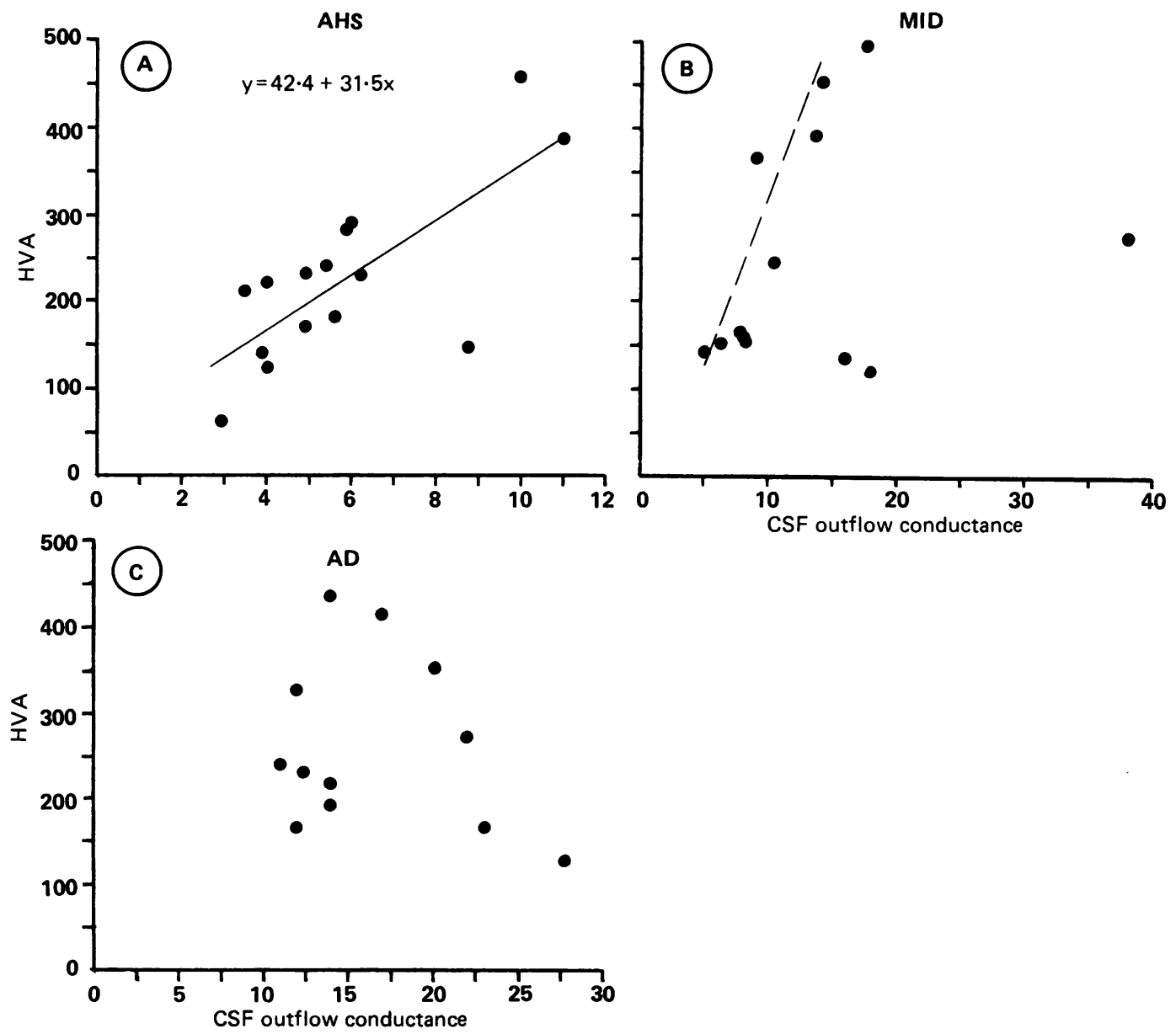
Figure 2a-c CSF 5hydroxyindoleacetic acid (5-HIAA) concentrations versus $C S F$ outflow conductance in patients with the adult hydrocephalus syndrome (fig $2 a$; linear regression, $n=15, r=+0 \cdot 73, p<$ $0.01)$, multiinfarct dementia (fig $2 b$; linear regression, $n=13$, $r=+0.13, p>0.6)$ and Alzheimer's disease (fig $2 c$; linear regression; $n=12, r=-0.09, p>$ $0 \cdot 7)$.

AHS

MID
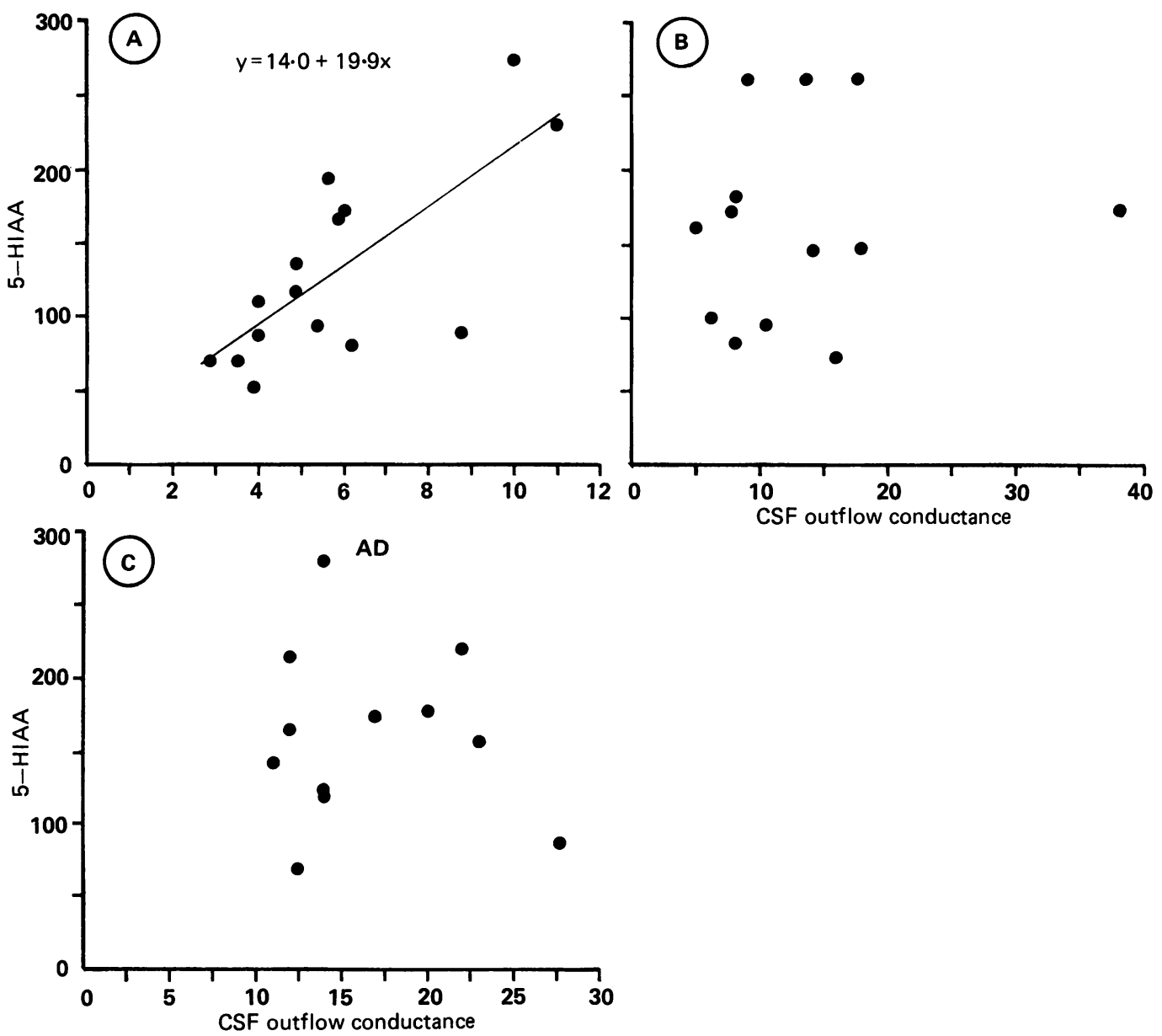

CSF outflow conductance

linear regression; $r=+0.73, p<0.01$ ), while no such relationship was observed in the MID and $\mathrm{AD}$ groups (fig $2 \mathrm{~b}-\mathrm{c}$ ).

Similarly, CSF lactic acid concentration correlated positively with CSF outflow conductance in the AHS group (fig 3a, linear regression, $r=+0.64, p<0.05)$ while no relationship was observed in the MID and AD groups (fig 3b-c).

No significant relationship was found between CSF MHPG concentrations and CSF outflow conductance $(p>0 \cdot 1)$. No significant relationship was observed for the transmitter and metabolic markers versus CSF resting pressure or CSF formation rate $(p>0 \cdot 1)$.

Influence of cognitive decline, walking disturbance, urine incontinence and functional grade on CSF transmitter and metabolic markers in the AHS group

A positive correlation was observed between CSF AChE activity and Minimental State Examination (MMSE) score (fig 4) in the AHS group (Linear regression; $\mathrm{r}=+0.55, \mathrm{p}<$ 0.05).

No significant relationship was observed for any of the assessed transmitter markers versus degree of gait dyspraxia, urine incontinence or ADL function $(p>0 \cdot 1)$ in the AHS patients.

Influence of degree of hydrocephalus and brain atrophy in the AHS group

No significant relationship was seen for the CSF transmitter and metabolic markers versus
Evans ratio, degree of cerebral atrophy or width of the third ventricle $(p>0 \cdot 1)$ in the AHS patients.

\section{Discussion}

CSF TRANSMITTER MARKERS AS INDICES OF HUMAN BRAIN NEUROTRANSMISSION

Lumbar CSF neurochemical measurements aim to serve as indirect in vivo markers of human central neurotransmission. ${ }^{29}$ This assumption is based on the following data (for a recent discussion, see Wester $e t a l^{30}$ ): a) manipulation of brain monoamine systems caused predictable CSF metabolite changes in animal models; b) rostrocaudal gradients for HVA and 5-HIAA ${ }^{31}$ and decreased lumbar concentrations of these substances after restricted CSF flow $^{32}$ were found in humans; c) positive correlations for HVA and 5-HIAA concentrations have been reported between lumbar CSF and human postmortem frontal cortex ${ }^{33}$ as well as for the parent monoamines and their metabolites between ventricular CSF and specific brain regions. ${ }^{30}$

These data suggest a specific topographic origin for monoamine neurotransmitters and their metabolites in human ventricular CSF and support the contention that CSF measurements are useful indices of central monoaminergic activity in humans.

CSF TRANSMITTER MARKERS IN AHS

Conflicting results have been observed when comparing differences in CSF transmitter 
Figure 3a-c CSF lactic acid concentrations versus CSF outflow conductance in patients with the adult hydrocephalus syndrome (fig $3 a$; linear regression, $n=13, r=+0.64, p<$ $0.05)$, multiinfarct dementia (fig 3b; linear regression, $n=11$, $r=-0.38, p>0 \cdot 2)$ and Alzheimer's disease (fig $3 c$; linear regression; $n=12, r=-0 \cdot 34, p>$ $0 \cdot 2)$.

Figure 4 CSF acetylcholinesterase activity ( $A C h E)$ versus minimental state examination (MMSE) in patients with the adult hydrocephalus syndrome, linear regression, $n=13$, $r=+0.55, p<0.05$.

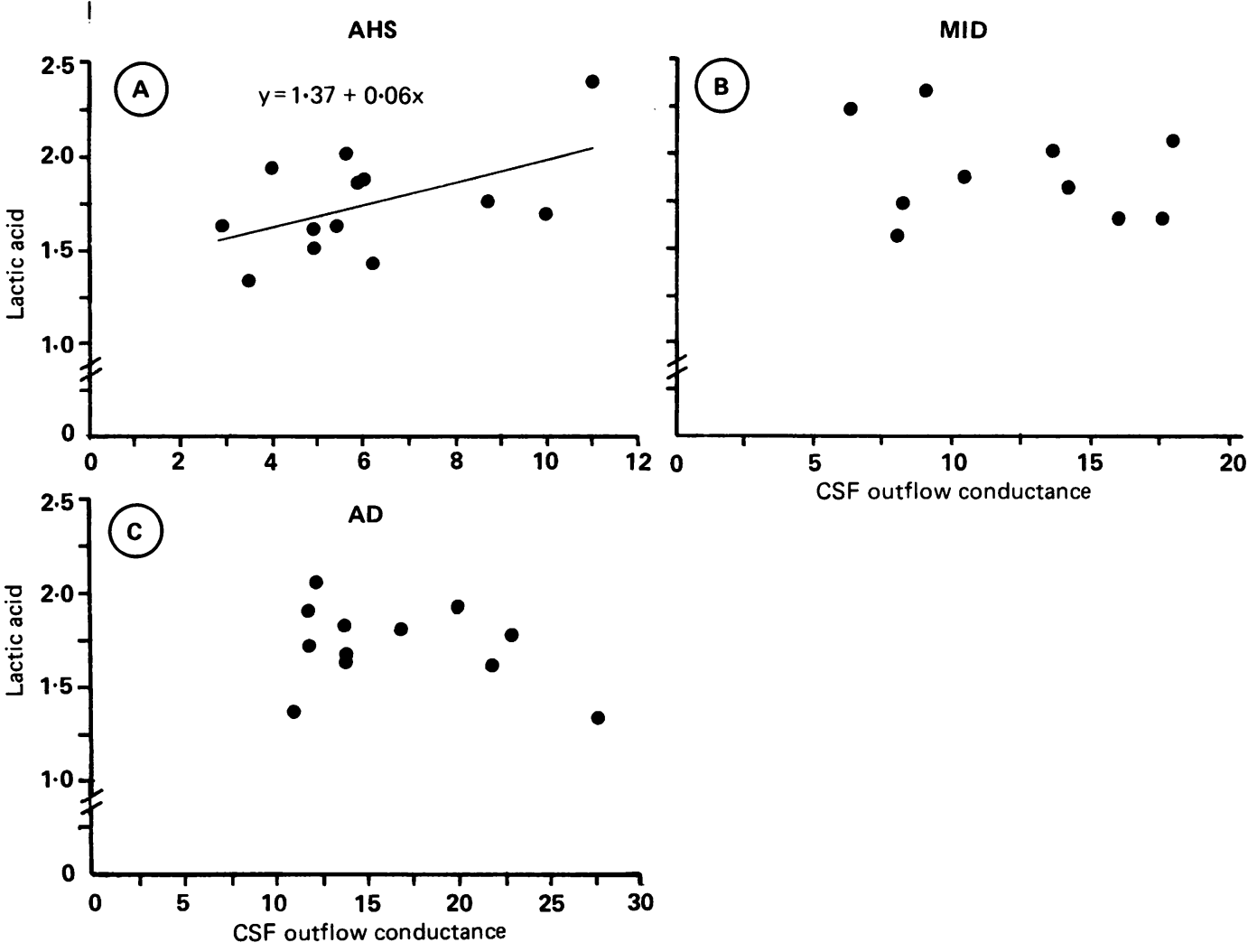

markers of patients with different kinds of dementia and Parkinson's disease. Thus decreased, no change or even increased CSF transmitter marker concentrations have been reported in these conditions. ${ }^{534}$ In previous studies of AHS patients, both normal ${ }^{15}$ and low levels of monoamine metabolites ${ }^{16}$ have been found. The lack of significant group differences of monoamines in this report does not support the idea of AHS with a specific monoaminergic neurochemical profile in CSF that would depict it from control subjects or patients with other types of dementia.

In contrast to the monoamine systems, AHS and $A D$ patients showed a similar decrease in CSF AChE activity compared with the controls, which suggests a common cholinergic disturbance in these two conditions. ${ }^{35}$

The decreased CSF AChE activities and CSF lactate concentrations and the non-significant trend of decreased CSF monoamine metabolite concentrations seen in the AHS group compared with the controls might be due

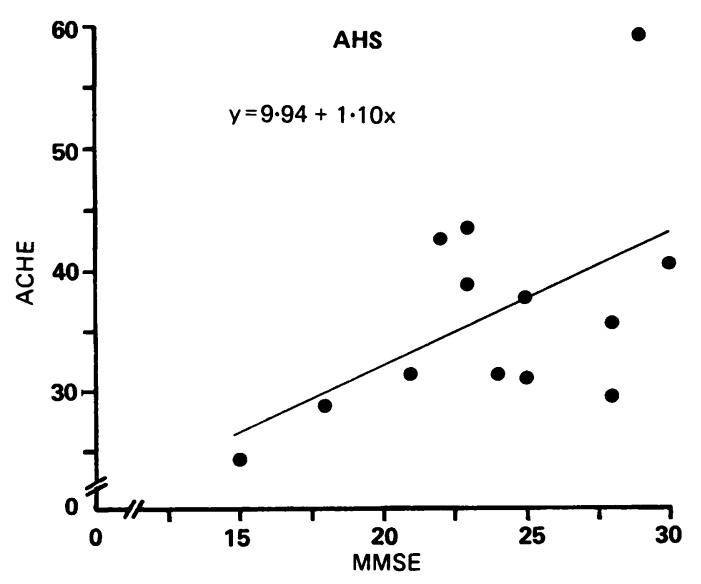

to some dilution effect of CSF with an increased sink effect causing diminished CSF concentrations. However, no significant relationship was seen for the transmitter and metabolic markers versus Evans ratio, width of the third ventricle or degree of hydrocephalus in the AHS group suggesting that a diluting effect of CSF would not be of major importance.

\section{CSF OUTFLOW CONDUCTANCE VERSUS CSF} TRANSMITTER MARKERS

In this study, significant positive correlations were found for concentrations of CSF HVA, CSF 5-HIAA and CSF lactic acid versus CSF outflow conductance in AHS patients (fig 1a, 2a, 3a). A similar pattern was also observed in the MID group with a low CSF conductance (fig 1b). According to a transport mechanism that follows the hydrostatic gradient between CSF and dural sinus blood, ${ }^{36}$ a low CSF conductance in the AHS patients, that is, an increased CSF outflow resistance, was predicted to compromise the clearance of CSF transmitter and metabolic markers with an accumulation of these substances in the CSF. However, our results are in contrast to this hypothesis and may instead be explained by one of the following theories, or a combination of them:

\section{Disturbance of CSF absorption at the} probenicid sensitive out-transport site The acidic metabolites HVA and 5-HIAA are transported out from the CSF into the bloodstream by an active transport mechanism, which can be blocked by probenicid. ${ }^{36}{ }^{37}$ The same active transport site is used by monocarboxylic acids such as lactic acid, ${ }^{38}$ while MHPG, a neutral glycol, diffuses freely through the CSF-brain and CSF-plasma barriers ${ }^{39}$ and is not probenicid sensitive. The exact 
anatomical location of this active transport site remains to be established. Two different major sites have been proposed, that is, the choroid plexus ${ }^{40}$ and the cerebral subarachnoid space. ${ }^{41}$ The positive correlation between concentrations of CSF HVA, CSF 5-HIAA and also CSF lactic acid versus CSF outflow conductance in the AHS group found in this study may be due to a various degree of stimulated out transport of the acidic solutes at the probenicid sensitive transport site. This implies an autoregulatory or compensatory CSF clearance mechanism in AHS patients with a facilitated out transport at the probenicid sensitive site.

\section{Inverse molecular flow in CSF}

In contrast to our data, Maira et $a l^{16}$ reported low lumbar CSF HVA concentrations in AHS patients, which were interpreted as an effect of an inverse, that is, caudorostral, molecular flow in CSF. This suggestion is supported by the finding of RISA-scint in AHS patients showing accumulation of the radioactive isotope in the ventricle system instead of over the convexities as seen in healthy subjects. ${ }^{42}$ Moreover, a positive correlation has been reported between decreased CSF outflow conductance, ventricular retention and absent parasagittal accumulation of a radioisotope at 24 hours. ${ }^{43}$ Thus a low CSF outflow conductance may be related to an inverse molecular flow in CSF. This would cause an accumulation of HVA in the ventricles and a subsequent transependymal absorption of the acidic metabolites. Thus an inverse molecular flow in CSF may explain the findings in our study with a relatively low lumbar CSF HVA and CSF 5HIAA concentrations related to a low CSF outflow conductance. It should, however, be pointed out that the extrapolation of RISAscint studies with heavy molecular weight tracers to the possible behaviour of smaller molecules such as the monoamines may be hazardous. ${ }^{40}$

\section{Disturbance of transport from the brain extracellular fluid to the ventricular CSF} An underlying hypertension and atherosclerotic cerebro-vascular disease has been proposed to be essential in the pathogenesis of idiopathic AHS. Ischaemia in the territory of the deep vessels in the brain could produce pathological changes ${ }^{45} 46$ with small periventricular infarctions, oedema, gliosis and demyelination and thereby create a transependymal barrier effect. ${ }^{478}$ Also the expansion and dilation of the vessels that produce the pumping action directing extracellular fluid (ECF) toward the ventricles in perivascular spaces ${ }^{49}$ may be reduced by atherosclerotic changes and certainly by an elevation of intraventricular pressure in developing hydrocephalus. This might lead to an obstacle to transependymal diffusion from ECF to CSF and also a trapping of ECF with its constituent of metabolic products including HVA, 5-HIAA and lactic acid.

\section{AHS VERSUS MID PATIENTS}

AHS and MID patients showed a similar pattern of hydrocephalus and a similar gait disturbance. However, the MID patients had a distinctive clinical and radiological picture of cerebrovascular disease with focal neurological signs, higher Hashinski score, more pronounced cognitive decline and old brain infarctions in five patients. In three out of six MID patients with a pathological low CSF outflow conductance (less than $10 \mathrm{~mm}^{3} \mathrm{kPa}^{1} \mathrm{sec}^{-1}$ ), a short and transient amelioration of clinical symptoms was observed after CSF tap-test. However, this could not be replicated in subsequent CSF tap tests and the patients were therefore not treated by operation. It was impossible to differentiate between the two MID groups with normal or abnormal outflow conductance according to case history, clinical signs or CT scan. Among MID patients with a low CSF conductance, a similar relationship as in the AHS group was observed with a positive correlation between the concentrations of CSF HVA versus the CSF conductance. This relationship in MID and AHS patients may be explained by the fact that some of the MID patients also had features of the AHS syndrome.

Our data support the idea that at least a subgroup of MID patients with dilated ventricles and disturbed CSF hydrodynamics are essentially equivalent to patients with AHS. ${ }^{46}$ This underlies the difficulties in differentiating MID and AHS patients, which may be underestimated in clinical practice, and may reflect the lack of a satisfactory definition for either of these conditions.

\section{AHS VERSUS AD PATIENTS}

More than half of the $15 \mathrm{AD}$ patients had a moderate hydrocephalus. The enlargement of the ventricles was due to cerebral atrophy. These patients therefore did not have any changes in CSF hydrodynamics in contrast to the AHS patients in whom a low CSF outflow conductance probably is essential. There are several other differences in the clinical symptomatology between AHS and AD patients. Thus while $\mathrm{AD}$ patients show a cognitive decline with the parietal and temporal lobes most affected, ${ }^{50}$ AHS patients exhibit a frontal lobe dementia with apathy, irritability, lethargy and confusion..$^{51}$ Furthermore, in AHS patients the dementia appears late in the disease progress, after the patient has gait dyspraxia, whereas in $\mathrm{AD}$ patients, the order of walking disturbance and dementia is reversed.

A cholinergic deficit in $\mathrm{AD}$ is well established, with a dysfunction of nucleus basalis of Meynert and its different projection areas. ${ }^{5-7}$ In this study, a significantly lower activity of CSF $\mathrm{AChE}$ was seen in both AHS and AD patients compared with controls. A positive relationship was also seen between CSF AChE activity and MMSE in the AHS patients. A similar relationship has been observed for AChE activity in $\mathrm{AD}$ patients, ${ }^{35} 52$ although this is not a consistent finding. ${ }^{35}$ Thus while the clinical picture in $A H S$ and $A D$ patients is different, the two groups seem to share a cholinergic CSF dysfunction. This dysfunction seems to be related to a brain neurochemistry dysfunction 
rather than CSF hydrodynamic changes, since we did not find a relationship between CSF AChE activity and CSF outflow conductance.

In conclusion, positive correlations were found between CSF HVA, CSF 5-HIAA and lactic acid concentrations versus CSF outflow conductance in AHS patients and also in MID patients with hydrocephalus. This implies that CSF hydrodynamic factors alter the CSF absorption and/or the distribution of these compounds, rather than factors such as the brain metabolism, ventricle size or neurodegeneration. We have also found a cholinergic dysfunction in both AHS and AD patients, which seems to link together these conditions biochemically despite the variability in their clinical features.

We thank Lars-Johan Liedholm, Lars Forsgren and Lars Sandman for diagnostic help and laboratory assistants Margandman for liagn and Karin Papworth for skillful technical gareta Danielsson and Karin Papworth for skillful technical assistance. This study was supported in part by the Swedish Heart and Lung foundation, King Gustaf V's 80th Anniversary tion for Stroke Research, Tore Nilssons and Karl-Oskar Hantion for Stroke Research, Tore Nilssons and Karl-Oskar Han-
sons foundations, Neurologiskt Handikappades Riksforbund in sons foundations, Neurologiskt Handikappades Riksforbund in
Sweden, the County Councils of Northern Sweden and the Medical Faculty of Umeå University.

1 Hakim S. Some observations on CSF pressure. Hydrocephalic syndrome in adults with "normal" CSF pressure. Bogota, Colombia, Javeriana Univ Sch Med, 1964.

2 Hakim S, Adams RD. The special clinical problem of symptomatic hydrocephalus with normal cerebrospinal fluid pressure. J Neurol Sci 1965;2:307-27.

3 Gjerris F, Boergesen, Soerensen P, eds. Outflow of cerebrospinal fluid. Copenhagen: Munksgaard, 1989:402-6.

4 Adams RD, Fisher CM, Hakim S, Ojemann RG, Sweet WH. Symptomatic occult hydrocephalus with "normal" cerebrospinal fluid pressure. A treatable syndrome. N Engl cerebrospinal fluid press
$J$ Med 1965;273:117-26.

5 Hardy J, Adolfsson R, Alafuzoff 1 , et al. Transmitter deficits in Alzheimer's disease. Neurochem Int 1985;7:545-63.

6 Bowen DM, Smith CB, White P, Davison AN. Neurotransmitter-related enzymes and indices of hypoxia in senile dementia and other abiotrophies. Brain 1976;99:459-96.

7 Davies P, Maloney AJ. Selective loss of central cholinergic neurons in Alzheimer's disease. Lancet 1976;ii: 1403.

8 Birkmeyer $W$, Hornykiewicz O. Der L-dioxyphenylalanin (=1-DOPA)-Effekt bei der Parkinson-Akinese. Wiener Klinische Wochenschrift 1961;73:787-8.

9 Hornykiewicz $O$. Neurochemistry of parkinsonism. In: Lajtha A, ed. Handbook of Neurochemistry, vol 7. New York: Plenum Press, 1972:465.

10 Sudarsky L, Simon S. Gait disorder in late-life hydrocephalus. Arch Neurol 1987;44:263-7.

11 Clough CG. A case of normal pressure hydrocephalus presenting as levodopa responsive Parkinsonism. J Neurol presenting as levodopa responsive

12 Ekstedt J, Friden H. CSF Hydrodynamics for the study of the adult hydrocephalus syndrome. In: Shapiro K, Marmarou A, Portnoy H, eds. Hydrocephalus. New York: Raven Press, 1984:363-82.

13 Borgesen SE. Conductance to outflow of CSF in normal pressure hydrocephalus. Acta Neurochir 1984;71:1-45.

14 Bannister R, Gilford E, Kocen R. Isotope encephalography in the diagnosis of dementia due to communicating hydrocephalus. Lancet 1967:1014-17.

15 Massarotti M, Roccella P. 5-hydroxyindolacetic acid and homovanillic acid levels in the cerebrospinal fluid of patients with normal pressure hydrocephalus (NPH); patients with normal pressure hydrocephalus

16 Maira G, Bareggi SR, Di Rocco C, Calderini G, Morselli PL. Monoamine acid metabolites and cerebrospinal fluid dynamics in normal pressure hydrocephalus. $J$ Neurol dynamics in normal pressure hydro
Neurosurg Psychiatry 1975;38:123-8.

17 Hachinski VC, Iliff LD, Zilhka E, et al. Cerebral blood flow in dementia. Arch Neurol 1975;32:632-7.

18 American Psychiatric Association. Diagnostic and statistical manual of mental disorders, 3rd ed. Washington DC American Psychiatric Association, 1980

19 McKhann G, Drachman D, Folstein M, Katzman R, Price D, Stadlan EM. Clinical diagnosis of Alzheimer's disease: Report of the NINCDS-ADRDA Work Group under the auspices of department of Health and human services Task force on Alzheimer's disease. Neurol 1984;34: 939-44.

20 Stein SC, Langfitt TW. Normal-pressure hydrocephalus. Predicting the results of cerebrospinal fluid shunting. $J$ Neurosurg 1974;41:463-70.

21 Folstein MF, Folstein SE, McHugh PR. Mini-Mental State. J Psychiat Res 1975;12:189-98.
22 Ekstedt J. CSF hydrodynamic studies in man. 1. Method of constant pressure CSF infusion. I Neurol Neurosurg Psychiatry 1977;40:105-19.

23 Wikkelsö C, Andersson H, Blomstrand C, Lindqvist G, Svendsen P. Normal pressure hydrocephalus, predictive value of the cerebrospinal fluid tap-test. Acta Neurol Scand 1986;73:566-73.

24 Wester P, Gottfries J, Johansson K, Klintebäck F, Winblad B. Simultaneous liquid chromatographic determination of seventeen of the major monoamine neurotransmitters, precursors and metabolites. I. Optimization of the mobile phase using factorial designs and a computer program to

25 wester P, Gottries J, Winblad B. Simultaneous liquid chromatographic determination of seventeen of the major monoamine neurotransmitters, precursors and monoamine neurotransmitters, precursors and
metabolites. II. Assessment of human brain cerebrospinal fluid concentrations. J Chromatogr 1987;415:275-88.

26 Ellman GL, Corutney KD, Andres V, Featherstone RM. A new and rapid colorimetric determination of acetylcholinesterase activity. Biochem Pharmacol 1961;7:88-95.

27 Noll F. L- ( + )-lactate. Determination with LDH, GPT and NAD. In: Bergmeyer HU, ed. Methods of enzymatic analysis. New York: Academic Press; 1974:1475.

28 Wilkinson L. SYSTAT: the system for statistics. Evanston, IL: SYSTAT Inc, 1986.

29 Wood JH. Neurochemical analysis of cerebrospinal fluid. Neurology 1980;30:645-51.

30 Wester P, Bergström U, Eriksson A, Gezelius C, Hardy J, Winblad B. Ventricular cerebrospinal fluid monoamine transmitter and metabolite concentrations reflect human brain neurochemistry in autopsy cases. J Neurochem brain neurochem

31 Sjöström R, Ekstedt J, Änggård E. Concentration gradients of monoamine metabolites in human cerebrospinal fluid. $J$ Neurol Neurosurg Psychiatry 1975;38:666-8.

32 Curzon G, Gumpert EJW, Sharpe DM. Amine metabolites in the lumbar cerebrospinal fluid of humans with restricted flow of cerebrospinal fluid. Nature 1971;231:189-91.

33 Stanley M, Traskman-Bendz L, Dorovini-Zis K. Correlations between aminergic metabolites simultaneously obtained from human CSF and brain. Life Sci 1985;37:1279-86.

34 Chase TN. Neurochemical alterations in Parkinson's disease. In: Wood JH, ed. Neurobiology of cerebrospinal fluid. New York: Plenum Press, 1980:207-18.

35 Hollander E, Mohs RC, Davis KL. Antemortem markers of Alzheimer's disease. Neurobiol Aging 1986;7:367-87.

36 Ebert MH, Kartzinel R, Cowdry RW, Goodwin FK Cerebrospinal fluid amine metabolites and probenicid test. In: Wood JH, ed. Neurobiology of cerebrospinal fluid. In: Wood JH, ed. Neurobiology of cereb

37 MacMillan V. Effect of probenicid on cerebral and cisternal cerebrospinal fluid lactate content. J Cereb Blood Flow Metab 1987;7:118-23.

38 MacMillan V, Leake J, Chung $T$, Bovell $M$. The effect of valproic acid on the 5-hydroxyindoleacetic, homovanillic acid and lactic acid levels of cerebrospinal fluid. Brain Res 1987;420:268-76.

39 Wolfson LI, Escriva A. Clearance of 3-methoxy-4-hydroxyphenylglycol from the cerebrospinal fluid. Neurology 1976;26:781-4.

40 Ashcroft GW, Dow RC, Moir ATB. The active transport of 5-hydroxyindole-3-acetic acid and 3-methoxy-4hydroxyphenylacetic acid from a recirculating perfusion system of the cerebral ventricles of the unanesthetised dog. J Physiol 1968;199:397-425.

41 Wolfson LI, Katzman R, Escriva A. Clearance of amine metabolites from the cerebrospinal fluid: the brain as metabolites from the cerebrospinal fluid:

42 Milhorat TH. Hydrocephalus and the cerebrospinal fluid. Baltimore: Williams and Wilkins, 1972.

43 Borgesen SE, Westergärd L, Gjerris F. Isotope cisternography and conductance to outflow of CSF in norma pressure hydrocephalus. ACTA Neurochir Wien 1981;57:67-73.

44 Di Chiro G, Hammock MK, Bleyer WA. Spinal descent of cerebrospinal fluid in man. Neurol 1976;26:1-8.

45 Davson H, Welch K, Segal MB. Physiology and pathophysiology of the cerebrospinal fluid. New York: Churchil Livingstone, 1987:879-86.

46 Graft-Radford NR, Godersky J. Idiopathic normal pressure hydrocephalus and systemic hypertension. Neurol 1987;37:868-71.

47 Akai K, Ochigasaki S, Tanaka O, Komatso A. Normal pressure hydrocephalus, neuropathological study. Acto pressure hydrocephalus, neur
Pathol Jpn 1987;37:97-110.

48 Di Rocco C, Di Trapani G, Maira G, Bentivoglio M, Macchi G, Rossi GF. Anatomo-clinical correlations in normotenG, Rossi GF. Anatomo-clinical correlations in norm
sive hydrocephalus. J Neurol Sci 1977;33:437-52.

49 Csert HF, Ostrach LH. Bulk flow of interstitial fluid after intracranial infection of blue dextran 2000. Exp Neurol 1974;45:50-60

50 Brun A, Englund E. Regional patterns of degeneration in Alzheimer's disease. Histopathology 1981;5:549-64.

51 Strub RL, Black FW, eds. Neurobehavioral disorders. A clinical approach. Philadelphia: FA Davis, 1988.

52 Wester P, Eriksson S, Forsell A, Puu G, Adolfsson R. Monoamine metabolite concentrations and cholinesterase activities in cerebrospinal fluid of progressive dementia patients: relation to clinical parameters. Acta Neurol Scand 1987;77:12-21. 